\title{
Assessing the mutagenicity of protic ionic liquids using the mini Ames test
}

\author{
Joshua E. S. J. Reid ${ }^{1,2}$, Neil Sullivan ${ }^{3}$, Lorna Swift ${ }^{4}$, Guy A. Hembury ${ }^{5}$, Seishi Shimizu ${ }^{1 *}$ and Adam J. Walker ${ }^{2^{*}}$
}

\begin{abstract}
Background: Protic ionic liquids (PILs) have been suggested as "greener" alternatives to conventional solvents in various industrial applications. In order to assess their suitability for such purposes, a thorough evaluation of their toxicity, mutagenicity, carcinogenicity and environmental impact is crucial. Whilst some studies have been published concerning the biodegradability and toxicity towards microorganisms of a limited number of PILs, no data concerning the mutagenicity of any PIL exist within the literature. As part of our ongoing studies into the toxicity and environmental impact of PILs, we quantify herein the mutagenic potential of a range of PILs through the mini Ames test.

Results: In total, 16 PILs and two precursor amines were assessed based on the Ames test, using Salmonella typhimurium strains TA98 and TA100. The 16 PILs used in this study included both carboxylate and chloride anions, as well as secondary and tertiary ammonium cations. Our results show that out of the 16 PILs, 15 gave negative results to the mini Ames test, concluding that they are unlikely to be either mutagenic or carcinogenic. The PIL N,N-Dimethylethanolammonium Octanoate ([DMEtA][Oct]) was toxic to both test strains, and its mutagenic potential could not be assessed by the mini Ames test. The two precursor amines, diethanolamine and $\mathrm{N}, \mathrm{N}$-dimethylethanolamine, gave negative results to the mini Ames tests despite the suggestion from other mutagenicity tests of diethanolamine's suggested carcinogenicity.

Conclusions: 15 PILs have been deemed likely to be neither mutagenic nor carcinogenic in accordance with the mini Ames test. We find that these results compare well to the relevant carboxylic acids and amines from the literature, suggesting that PILs exist as well solvated ions in these test conditions, similar to those of their precursors in the same test. From this, we caution the use of secondary ammonium cations in PILs, as certain secondary amines have been suggested to be potentially carcinogenic, despite their results from the mini Ames test.
\end{abstract}

Keywords: Protic ionic liquids, Mini Ames test, Mutagenicity, Green solvents

\section{Background}

The development of new chemical processes and applications, that are not only efficient but also pose a low hazard to both humans and the environment, forms a cornerstone of sustainable chemistry [1]. With the growing pressure from chemical legislation such as REACh in Europe, manufacturers are now strongly encouraged to find safer, alternative chemicals whenever possible. As a result, research into alternative, more sustainable and

\footnotetext{
*Correspondence: seishi.shimizu@york.ac.uk; adam.walker@twi.co.uk ${ }^{1}$ York Structural Biology Laboratory, Department of Chemistry, University of York, Heslington, York YO10 5DD, UK

2 TWI Ltd., Granta Park, Great Abington, Cambridge CB21 6AL, UK Full list of author information is available at the end of the article
}

environmentally benign materials has grown considerably. Challenges such as reducing volatile organic compound (VOC) and greenhouse gas (GHG) emissions as well as decreasing the dependence of hazardous materials still persist for many chemical processes. Many common organic solvents of previous wide application, such as chloroform, 1,2-dichloroethane, benzene and hexamethylphosphoramide (HMPA), are now well-established as carcinogenic and their use has been restricted correspondingly. Replacing such materials with safer but equally effective solvents represents an ongoing challenge for the chemical industry, and a number of "neoteric" classes of solvent have thus emerged in recent years as potential alternatives-amongst them, supercritical fluids (SCFs) and ionic liquids (ILs) [3-5]. ILs, which are

\section{Chemistry Central}

(c) 2015 Reid et al. This article is distributed under the terms of the Creative Commons Attribution 4.0 International License (http://creativecommons.org/licenses/by/4.0/), which permits unrestricted use, distribution, and reproduction in any medium, provided you give appropriate credit to the original author(s) and the source, provide a link to the Creative Commons license, and indicate if changes were made. The Creative Commons Public Domain Dedication waiver (http://creativecommons.org/ publicdomain/zero/1.0/) applies to the data made available in this article, unless otherwise stated. 
effectively low-melting salts, fall into two main chemical classes: aprotic ILs and protic ILs (PILs).

Typically, PILs are prepared from the reversible proton equilibrium between a Brønsted acid and an appropriate proton acceptor. This relatively quick and simple preparation is preferential to the multi-stage aprotic IL synthesis, as it avoids the use of stoichiometric quantities of highly toxic alkylation agents. The direct synthesis method can also minimise the presence of water in the product [6], known to have drastic effects on the IL's properties $[7,8]$. This simple method for high purity preparation of PILs ultimately makes them much cheaper to produce than their aprotic counterparts $[9,10]$. Even though they have been known for over a century [11], only very recently has their potential begun to be recognized [12-17]. The number of possible PIL structures is immense, arising from all the possible appropriate combinations of precursors. The physical and solvation properties of a PIL within the medium and at interfaces can therefore be modified with an appropriate selection of precursors. With such a wide variety of potential molecular structures, it is hard to generalise properties of protic ionic liquids. It is likely however that an extensive hydrogen bonding network exists in the condensed phase [18]. This has led to a variety of published case studies of their applications such as natural product extraction [19-24], desulfurization of fuel [25-27], absorbents for coolingheating cycles [28], $\mathrm{CO}_{2}$ capture [29,30], anhydrous fuel cell electrolytes [31-33], catalysis [4, 34, 35], lubrication [36-40] and hydrometallurgy [41-44].

What makes PILs particularly attractive is their suggested low toxicity according to numerous in vitro case studies. Previously, a number of PILs (including primary, secondary and tertiary 2-hydroxylethylamines with carboxylate anions of various alkyl chain lengths) have been subject to tests to assess their toxicity towards a wide variety of organisms, such as soil microorganisms and terrestrial plants, marine bacteria, aquatic plants and rat leukaemia cells [45-47]. In these studies, the PILs generally displayed relatively high $\mathrm{EC}_{50}$, implying that they are generally less toxic than the aprotic ILs also studied. Recently, quantitative structure activity relationship (QSAR) analysis has been used to successfully estimate the toxicity of some PILs in a number of tests [48]. While the toxicity of PILs have been explored for a number of structures, the mutagenicity of PILs has not been investigated. Mounting evidence suggest that the mutagenic potential of a substance can be used as an indicator of its carcinogenicity [49], and the strong correlation between mutagenicity and carcinogenicity of compounds has led to the development of the Ames test. By observing the effect of a chemical substance on the growth of particular strains of Salmonella typhimurium in specific test environments, it is possible to identify if a chemical substance can induce gene mutation within microorganisms. The results of these tests are used to calculate the mutagenic potential of a test material, which is utilised by regulatory agencies when assessing the risk associated with the use of chemical substances [49-53].

At present, we are only aware of one prior study into the mutagenic potential of ILs carried out by Docherty et al. [54]. Using the Ames test, they found that none of the ILs in their selection of imidazolium, pyridinium and quaternary ammonium bromide salts were mutagenic (Table 1). Unfortunately, there is no information relating the structure of the anion to mutagenic potential. This is an important issue to address in the interest of benign ionic liquid design for chemical processes. They summarise with the importance of the Ames test as a means for screening new, potentially environmentally benign green solvents. If we are to successfully apply these materials, we must understand any safety concerns they pose. To this end, we have screened 16 PILs for mutagenicity using the mini Ames test to better understand the potential risks associated with exposure to these materials. The precursor amines diethanolamine and $\mathrm{N}, \mathrm{N}$-dimethylethanolamine are also included in our mini Ames test screening, to better understand the relation of the precursor materials to the resulting PIL.

\section{Experimental section Materials}

The names and abbreviations of the 16 PILs chosen for this study are shown in Table 2. The corresponding structures of all cations and anions of the PILs studied are shown in Fig. 1. The anion variation covers a number of common carboxylate structures as well as the chloride anion, while the cation selection includes both secondary and tertiary ammonium cations all featuring either alcohol or ether functional groups (Tables 3, 4).

The amines N-methyl-N-ethylethanolamine and $\mathrm{N}$-methyl-bis(2-methoxyethyl)amine were purchased from Almac Sciences Ltd., Craigavon, UK. All other materials including carboxylic acids, secondary amines and tertiary amines were supplied by Sigma Aldrich Ltd., Gillingham, UK. All materials were of analytical grade and used without further purification.

\section{Synthesis of PILs}

All carboxylate PILs were prepared from the equimolar neutralization reaction between the corresponding precursor acid and amine as previously described [12]. The chloride PILs were prepared by bubbling an excess of dry $\mathrm{HCl}$ gas (generated from sodium chloride and sulfuric acid in a Kipps apparatus) through the appropriate amine, followed by removal of the excess acid in vacuo. Purity of 14 of the 16 PILs was assessed using ion 
Table 1 Mutagenic Index (MI) for 10 aprotic ionic liquids as determined from the Ames test screening as reported by Docherty et al. [53]

\begin{tabular}{llllc}
\hline Ionic liquid & MI (TA98) & MI (TA98 + S9) & MI (TA100) & MI (TA100 + S9) \\
\hline 1-Butyl-3-methylimidazolium bromide & $0.86 \pm 0.18$ & $0.88 \pm 0.20$ & $1.15 \pm 0.17$ & $0.88 \pm 0.15$ \\
1-Hexyl-3-methylimidazolium bromide & $0.99 \pm 0.37$ & $0.84 \pm 0.10$ & $0.92 \pm 0.05$ & $1.21 \pm 0.23$ \\
1-Octyl-3-methylimidazolium bromide & $1.55 \pm 0.28$ & $0.85 \pm 0.24$ & $1.09 \pm 0.13$ & $1.13 \pm 0.10$ \\
1-Butyl-3-methyl pyridinium bromide & $1.07 \pm 0.10$ & $0.93 \pm 0.13$ & $1.39 \pm 0.30$ & $1.34 \pm 0.04$ \\
1-Hexyl-3-methyl pyridinium bromide & $1.16 \pm 0.34$ & $1.09 \pm 0.13$ & $1.27 \pm 0.18$ & $1.08 \pm 0.19$ \\
1-Octyl-3-methyl pyridinium bromide & $1.27 \pm 0.42$ & $1.01 \pm 0.11$ & $1.34 \pm 0.28$ & $0.89 \pm 0.01$ \\
Tetramethylammonium bromide & $1.47 \pm 0.26$ & $0.90 \pm 0.07$ & $1.07 \pm 0.13$ & $1.16 \pm 0.25$ \\
Tetraethylammonium bromide & $1.33 \pm 0.28$ & $1.74 \pm 0.29$ & $1.04 \pm 0.03$ & $1.26 \pm 0.07$ \\
Tetrabutylammonium bromide & $1.07 \pm 0.21$ & $1.14 \pm 0.35$ & $1.19 \pm 0.06$ & $1.19 \pm 0.02$ \\
Tetrahexylammonium bromide & $1.21 \pm 0.80$ & $0.70 \pm 0.18$ & $1.09 \pm 0.08$ & $0.82 \pm 0.09$ \\
\hline
\end{tabular}

The results are from concentrations of $1 \mathrm{mg} /$ plate, aside from Tetrahexylammonium bromide which was tested at $0.01 \mathrm{mg} / \mathrm{plate}$ as higher concentrations were toxic to the bacterial strains

Table 2 Names and abbreviations of the PILs used in this study

\begin{tabular}{ll}
\hline PIL name & Abbreviation \\
\hline $\mathrm{N}, \mathrm{N}$-dimethylethanolammonium acetate & {$[\mathrm{DMEtA}][\mathrm{OAc}]$} \\
$\mathrm{N}, \mathrm{N}$-dimethylethanolammonium propionate & {$[\mathrm{DMEtA}][\mathrm{Pr}]$} \\
$\mathrm{N}, \mathrm{N}$-dimethylethanolammonium hexanoate & {$[\mathrm{DMEtA}][\mathrm{Hex}]$} \\
$\mathrm{N}, \mathrm{N}$-dimethylethanolammonium octanoate & {$[\mathrm{DMEtA}][\mathrm{Oct}]$} \\
$\mathrm{N}, \mathrm{N}$-dimethylethanolammonium glycolate & {$[\mathrm{DMEtA}][\mathrm{Gly}]$} \\
$\mathrm{N}, \mathrm{N}$-dimethylethanolammonium succinate & {$[\mathrm{DMEtA}][\mathrm{Succ}]$} \\
$\mathrm{N}, \mathrm{N}$-dimethylethanolammonium chloride & {$[\mathrm{DMEtA}][\mathrm{Cl}]$} \\
$\mathrm{N}$-methyl-N-ethylethanolammonium acetate & {$[\mathrm{EMEtA}][\mathrm{OAc}]$} \\
$\mathrm{N}, \mathrm{N}$-diethylethanolammonium acetate & {$[\mathrm{DEEtA}][\mathrm{OAc}]$} \\
$\mathrm{N}$-butyldiethanolammonium acetate & {$[\mathrm{BDEtA}][\mathrm{OAc}]$} \\
$\mathrm{N}$-methyl-bis(2-methoxyethyl)ammonium acetate & {$[\mathrm{MDEOMA}][\mathrm{OAc}]$} \\
$\mathrm{N}$-methylethanolammonium acetate & {$[\mathrm{MEtA}][\mathrm{OAc}]$} \\
Diethanolammonium acetate & {$[\mathrm{DEtA}][\mathrm{OAc}]$} \\
Diethanolammonium chloride & {$[\mathrm{DEtA}][\mathrm{Cl}]$} \\
Bis(2-methoxyethyl)ammonium acetate & {$[\mathrm{DEOMA}][\mathrm{OAc}]$} \\
Bis(2-methoxyethyl)ammonium chloride & {$[\mathrm{DEOMA}][\mathrm{Cl}]$} \\
\hline
\end{tabular}

chromatography to demonstrate the high purity achievable using this synthesis method. The results of this are recorded in the Additional file 1.

\section{Mini Ames test}

The mini Ames test was carried out on the 16 PILs by Complement Genomics Ltd, The Durham Genome Centre, Park House, Station Road, Lanchester, Co. Durham, UK, DH7 OEX. The purpose of the mini-Ames test is the detection of mutations in specialised strains of Salmonella typhimurium that restore their ability to synthesise the amino acid histidine; hence the mutated bacteria are identified through their ability to grow in the absence of this essential amino acid. By using two different modified strains of S. typhimurium, TA98 and TA100, we can test for both frameshift and base pair mutations, respectively. The study of the development of mutations through the mini-Ames test can be applied to organic solvents to determine mutagenic potential, which can then be used as an indicator of likely carcinogenicity [53].

Because the mini-Ames test species are prokaryotic organisms and the tests are carried out in vitro, the results cannot provide direct information on the mutagenic and subsequent carcinogenic potency of a substance in mammals; however, despite the correlation not being absolute, many compounds that are positive in the mini-Ames test are also mammalian carcinogens.

Cultures of Salmonella typhimurium TA98 (to detect frameshift mutations) and TA100 (to detect missense mutations) strains were grown to late exponential phase of growth (approximately $10^{9}$ cells per $\mathrm{ml}$ ) at $37^{\circ} \mathrm{C}$ with $25 \mu \mathrm{g} \mathrm{ml}^{-1}$ ampicillin to select for the R-factor (plasmids carrying antibiotic resistance genes [55]). The developed strains yielded spontaneous revertant colony plate counts which were found to be consistent with the laboratory's historical control data. Bacteria were exposed to the PILs both in the presence and absence of an S9 metabolic activation system, prepared from the livers of rats treated with the enzyme-inducing agent Aroclor 1254. The PILs were added directly to the test system in various concentrations; we exceeded recommended maximum test concentration for soluble non-cytotoxic substances $(5 \mu \mathrm{L} /$ plate; OECD 471$)$ and all calculations are based on test concentrations of $15 \mu \mathrm{L} /$ plate when possible. In addition, Positive control concentrations of 2-amino-fluorene in DMSO and sodium azide in water were used to demonstrate the 
<smiles>C[NH+](C)CCO</smiles>

[DMEtA]<smiles>CCCC[NH+](CCO)CCO</smiles><smiles>COCC[NH+](C)CCOC</smiles>

[MDEOMA]<smiles>OCC[NH2+]CCO</smiles>

[DEtA]<smiles>CC[NH+](C)CCO</smiles>

[EMEtA]<smiles>CCCC[NH+](CC)CCO</smiles><smiles>C[NH2+]CCO</smiles>

[MEtA]<smiles>CC(=O)[O-]</smiles>

[OAc]<smiles>CCC(=O)[O-]</smiles>

$[\mathrm{Pr}]$<smiles>CCCCCCCCCC(=O)[O-]</smiles>

[Gly]<smiles>COCCNCCOC</smiles>

[DEOMA]<smiles>CCCCCCCC(=O)O</smiles>

[Oct]

Fig. 1 Structures and abbreviations of cations and anions used to prepare each PIL in this study

effective performance of each assay used for TA98 and TA100, respectively.

The given bacterial culture $(0.01 \mathrm{~mL})$, either sterile buffer or the metabolic activation system $(0.05 \mathrm{~mL})$ and the test PIL (up to $0.015 \mathrm{~mL}$ ) were pre-incubated for $20 \mathrm{~min}$ at $30^{\circ} \mathrm{C}$, after which the system was mixed with a top agar $(2 \mathrm{~mL})$ before being transferred onto the surface of a minimal agar plate. All plates were then incubated at $37^{\circ} \mathrm{C}$ for $48 \mathrm{~h}$, after which, the number of revertant colonies per plate was counted and compared to the control plates. Each assay was performed in triplicate.

By comparing the number of revertant colonies in the presence of the PIL at the highest measured dosage $\left(R_{P I L}\right)$ to the number of spontaneous revertant colonies $\left(R_{S}\right)$, the mutagenicity of each PIL was evaluated. By calculating the Mutagenicity Index (MI) (Eq. 1) for each PIL, the 
Table 3 Mutagenicity Index (MI) and Mutagenic Activity Ratio (MAR) with the TA98 test strains of S. typhimurium at 5 $\mu$ L/ plate both with and without S9 metabolic activation for all PILs and selected precursors in this study

\begin{tabular}{|c|c|c|c|c|}
\hline \multirow[t]{3}{*}{ PIL } & \multirow{2}{*}{\multicolumn{2}{|c|}{$\begin{array}{l}\text { TA } 98 \\
\text { Mutagenicity Index (MI) }\end{array}$}} & \multirow{2}{*}{\multicolumn{2}{|c|}{$\begin{array}{l}\text { TA98 } \\
\text { Mutagenic Activity Ratio (MAR) }\end{array}$}} \\
\hline & & & & \\
\hline & - & 59 & - & \$9 \\
\hline [DMEtA][OAc] & $0.95 \pm 0.22$ & $0.84 \pm 0.43$ & $-0.03 \pm 0.008$ & $-0.44 \pm 0.144$ \\
\hline [DMEtA][Pr] & $0.59 \pm 0.15$ & $0.27 \pm 0.17$ & $-0.53 \pm 0.094$ & $-1.64 \pm 1.126$ \\
\hline [DMEtA][Hex] & $0.23 \pm 0.18$ & $1.10 \pm 0.26$ & $-0.28 \pm 0.193$ & $0.06 \pm 0.009$ \\
\hline [DMEtA][Oct] & - & - & - & - \\
\hline [DMEtA][Gly] & $1.64 \pm 0.15$ & $0.52 \pm 0.29$ & $1.00 \pm 0.149$ & $-0.89 \pm 0.181$ \\
\hline [DMEtA][Succ] & $0.82 \pm 0.14$ & $6.33 \pm 2.50$ & $-0.78 \pm 0.084$ & $1.78 \pm 1.267$ \\
\hline [DMEtA][Cl] & $2.10 \pm 0.26$ & $0.56 \pm 0.36$ & $2.83 \pm 0.237$ & $-0.22 \pm 0.151$ \\
\hline [EMEtA][OAc] & $0.95 \pm 0.30$ & $1.40 \pm 0.46$ & $-0.02 \pm 0.004$ & $0.33 \pm 0.047$ \\
\hline [DEEtA][OAc] & $2.03 \pm 0.08$ & $3.05 \pm 0.42$ & $0.55 \pm 0.015$ & $2.39 \pm 0.466$ \\
\hline [BDEtA][OAc] & $0.83 \pm 0.21$ & $1.00 \pm 0.20$ & $-0.18 \pm 0.032$ & $0.00 \pm 0.000$ \\
\hline$[\mathrm{MDEOMA}][\mathrm{OAc}]$ & $2.69 \pm 0.87$ & $0.63 \pm 0.37$ & $0.45 \pm 0.161$ & $-0.17 \pm 0.084$ \\
\hline$[\mathrm{MEtA}][\mathrm{OAc}]$ & $0.36 \pm 0.39$ & $0.90 \pm 0.72$ & $-0.15 \pm 0.052$ & $-0.06 \pm 0.035$ \\
\hline$[\mathrm{DEtA}][\mathrm{OAc}]$ & $0.88 \pm 0.53$ & $1.36 \pm 0.62$ & $-0.03 \pm 0.010$ & $0.22 \pm 0.132$ \\
\hline$[\mathrm{DEtA}][\mathrm{Cl}]$ & $1.00 \pm 0.25$ & $0.70 \pm 0.69$ & $0.00 \pm 0.000$ & $-0.17 \pm 0.112$ \\
\hline [DEOMA][OAc] & $1.11 \pm 0.35$ & $1.30 \pm 0.32$ & $0.07 \pm 0.031$ & $0.50 \pm 0.176$ \\
\hline [DEOMA][Cl] & $1.69 \pm 0.67$ & $0.96 \pm 0.24$ & $0.03 \pm 0.010$ & $-0.06 \pm 0.016$ \\
\hline Diethanolamine & $0.48 \pm 0.48$ & $1.78 \pm 0.54$ & $-0.18 \pm 0.083$ & $0.39 \pm 0.112$ \\
\hline $\mathrm{N}, \mathrm{N}$-dimethylethanolamine & $0.74 \pm 0.46$ & $0.17 \pm 0.15$ & $-0.32 \pm 0.143$ & $-1.94 \pm 0.970$ \\
\hline
\end{tabular}

Table 4 Mutagenicity Index (MI) and Mutagenic Activity Ratio (MAR) with the TA100 test strains of S. typhimurium at 5 $\mu$ L/ plate both with and without S9 metabolic activation for all PILs and selected precursors in this study

\begin{tabular}{|c|c|c|c|c|}
\hline \multirow[t]{3}{*}{ Code } & \multirow{2}{*}{\multicolumn{2}{|c|}{$\begin{array}{l}\text { TA } 100 \\
\text { Mutagenicity Index (MI) }\end{array}$}} & \multirow{2}{*}{\multicolumn{2}{|c|}{$\begin{array}{l}\text { TA } 100 \\
\text { Mutagenic Activity Ratio (MAR) }\end{array}$}} \\
\hline & & & & \\
\hline & - & S9 & - & \$9 \\
\hline [DMEtA][OAc] & $1.10 \pm 0.02$ & $1.13 \pm 0.14$ & $0.11 \pm 0.003$ & $0.15 \pm 0.010$ \\
\hline [DMEtA][Pr] & $0.99 \pm 0.08$ & $1.45 \pm 0.19$ & $-0.01 \pm 0.001$ & $0.46 \pm 0.220$ \\
\hline [DMEtA][Hex] & $0.07 \pm 0.08$ & $0.15 \pm 0.03$ & $-0.95 \pm 0.149$ & $-0.96 \pm 0.091$ \\
\hline [DMEtA][Oct] & - & - & - & - \\
\hline [DMEtA][Gly] & $0.74 \pm 0.16$ & $1.65 \pm 0.10$ & $-0.42 \pm 0.024$ & $0.35 \pm 0.059$ \\
\hline [DMEtA][Succ] & $1.09 \pm 0.05$ & $0.99 \pm 0.08$ & $0.14 \pm 0.003$ & $-0.01 \pm 0.001$ \\
\hline$[\mathrm{DMEtA}][\mathrm{Cl}]$ & $1.11 \pm 0.22$ & $1.04 \pm 0.08$ & $0.15 \pm 0.026$ & $0.02 \pm 0.003$ \\
\hline$[\mathrm{EMEtA}][\mathrm{OAc}]$ & $0.95 \pm 0.12$ & $1.14 \pm 0.05$ & $-0.06 \pm 0.003$ & $0.16 \pm 0.020$ \\
\hline [DEEtA][OAc] & $0.73 \pm 0.06$ & $0.74 \pm 0.05$ & $-0.69 \pm 0.058$ & $-0.64 \pm 0.080$ \\
\hline [BDEtA][OAc] & $1.01 \pm 0.10$ & $1.30 \pm 0.30$ & $0.01 \pm 0.001$ & $0.32 \pm 0.060$ \\
\hline [MDEOMA][OAc] & $1.09 \pm 0.09$ & $0.88 \pm 0.33$ & $0.09 \pm 0.005$ & $-0.09 \pm 0.010$ \\
\hline$[\mathrm{MEtA}][\mathrm{OAc}]$ & $0.96 \pm 0.13$ & $1.02 \pm 0.22$ & $-0.02 \pm 0.002$ & $0.01 \pm 0.003$ \\
\hline [DEtA][OAc] & $0.68 \pm 0.09$ & $0.83 \pm 0.06$ & $-0.23 \pm 0.037$ & $-0.09 \pm 0.011$ \\
\hline [DEtA][Cl] & $1.32 \pm 0.09$ & $1.11 \pm 0.16$ & $0.20 \pm 0.009$ & $0.06 \pm 0.011$ \\
\hline [DEOMA][OAc] & $1.48 \pm 0.10$ & $0.85 \pm 0.04$ & $0.24 \pm 0.028$ & $-0.27 \pm 0.025$ \\
\hline [DEOMA][Cl] & $1.21 \pm 0.16$ & $0.54 \pm 0.11$ & $0.14 \pm 0.010$ & $-0.85 \pm 0.020$ \\
\hline Diethanolamine & $1.50 \pm 0.17$ & $0.51 \pm 0.11$ & $0.26 \pm 0.032$ & $-0.85 \pm 0.217$ \\
\hline $\mathrm{N}, \mathrm{N}$-dimethylethanolamine & $0.66 \pm 0.20$ & $0.41 \pm 0.08$ & $-0.22 \pm 0.052$ & $-0.22 \pm 0.048$ \\
\hline
\end{tabular}


relative mutagenicity (according to each bacterial strain) can be compared for all PILs in this study [56].

$$
M I=\frac{R_{P I L}}{R_{s}}
$$

A further assessment of the data was the calculation of the Mutagenic Activity Ratio (MAR). Recommended by the US National Enforcement Investigations Centre, it has been suggested that a MAR $\geq 2.5$ indicates a $95 \%$ probability of likely carcinogenicity in test animals [56].

$$
M A R=\frac{R_{P I L}-R_{S}}{R_{H}}
$$

where $R_{H}$ is the historical laboratory number for spontaneous revertant colonies. The complete data of all compounds screened with the mini Ames test in this study have been compiled into Additional file 1 .

\section{Results and discussion}

In order for a compound to be classified as mutagenic according to the mini-Ames test, it must fulfil the following three criteria:

1. A significant correlation between test concentration of substance and the number of revertant colonies.

2. At least a twofold increase in the number of revertant colonies at the maximum test concentration.

3. The Mutagenicity Index (MI) and the Mutagenic Activity Ratio (MAR) of each substance must be greater than 2.0 and 2.5 , respectively, at the maximum test concentration.

The MI and MAR results of each PIL in the TA98 strain and TA100 strain are summarised in Tables 3 and 4, respectively. Of the 16 screened PILs, 15 of them did not meet all three criteria. This means that these 15 PILs are likely to be non-mutagenic and non-carcinogenic as far as can be determined by the mini-Ames test. For some of the PILs, there are some test results where the $\mathrm{MI}$ and/or the MAR values are greater than the threshold as outlined in criteria point 3 . However, because no PIL complied with criteria point 1 , none of the PILs could be suggested to be mutagenic as a result of this study.

The PILs chosen for the purposes of this study were selected on the basis of assessing the effects of both anion and cation on the results of the mini-Ames test, which will be discussed in the following sections. The PILs selected for this work were based upon commercially available amine and acid precursors (or simple derivatives thereof), hence in many cases extensive toxicological data are available for these materials [57-60]. We hypothesise that the mutagenicity of PILs will be relatable to that of their precursors. Stange et al. has studied the binary system of triethylammonium methanesulfonate and water at various compositions using far infrared (FIR) spectroscopy and relation to density fluctuation theory (DFT) calculations of bond energy and frequencies [61]. They found that the PIL prefers to be in a solvent-separated ion pair structure as oppose to a contact-ion pair at around $80 \%$ mole fraction of water. We expect that in similar aqueous conditions the PILs in this study would also exhibit the same solvent-separated ion pair structure. The conditions for the mini Ames test are designed to simulate the effects of these compounds at dilute concentrations. In this well solvated aqueous environment, we would expect the interactions between ions would be far less favourable than the interactions between ions. As a result, the mutagenic potential of a fully miscible PIL in the mini Ames test will be dependant more on the structure of the individual ions than the PILs ability to form aqueous macrostructures. To this end, we believe that the information of the Ames test results for the precursor materials used to produce a given PIL will be crucial in predicting the likely mutagenicity of a PIL.

Given that, at low concentrations and at physiological $\mathrm{pH}$, the protonation state of the precursors and the PIL components would (assuming the PIL is fully water miscible) be identical. The mutagenic and carcinogenic potential of PILs might be expected to additively mirror that of its two molecular precursor chemicals.

\section{Cations and mutagenicity}

Here we assess the effect of cation structure on the resulting mutagenicity of the PIL. This is made possible by our selection of PILs; 8 of which contain a common anion, acetate. By Increasing the length of the alkyl side chains on the cation ([DMEta][OAc] to [EMEtA][OAc] to $[\mathrm{DEEtA}][\mathrm{OAc}])$ - and hence increasing lipophilicityresulted in an increase in the MI with the TA98 strain both with and without the activating agent. This increase was consistent to the point where [DEEtA] $[\mathrm{OAc}]$ passed the MI requirement for both TA98 tests (Fig. 2). However, as this PIL did not meet the remaining requirements as outlined above, it cannot be deemed mutagenic to this particular test strain. Interestingly, the PIL [BDEtA] [OAc] did not show the same behaviour, despite having a longer aliphatic chain within its structure compared to all other hydroxyl functionalised cations in this study. This suggests that the use of hydroxyl functional groups can counteract the effects of an increased alkyl chain length on the resulting MI and MAR of the PIL. The incorporation of polar functional groups in IL cation structures has been linked to a reduction in observed toxicity, so it is reasonable that observed mutagenicity also decreases in a similar manner $[62,63]$. 


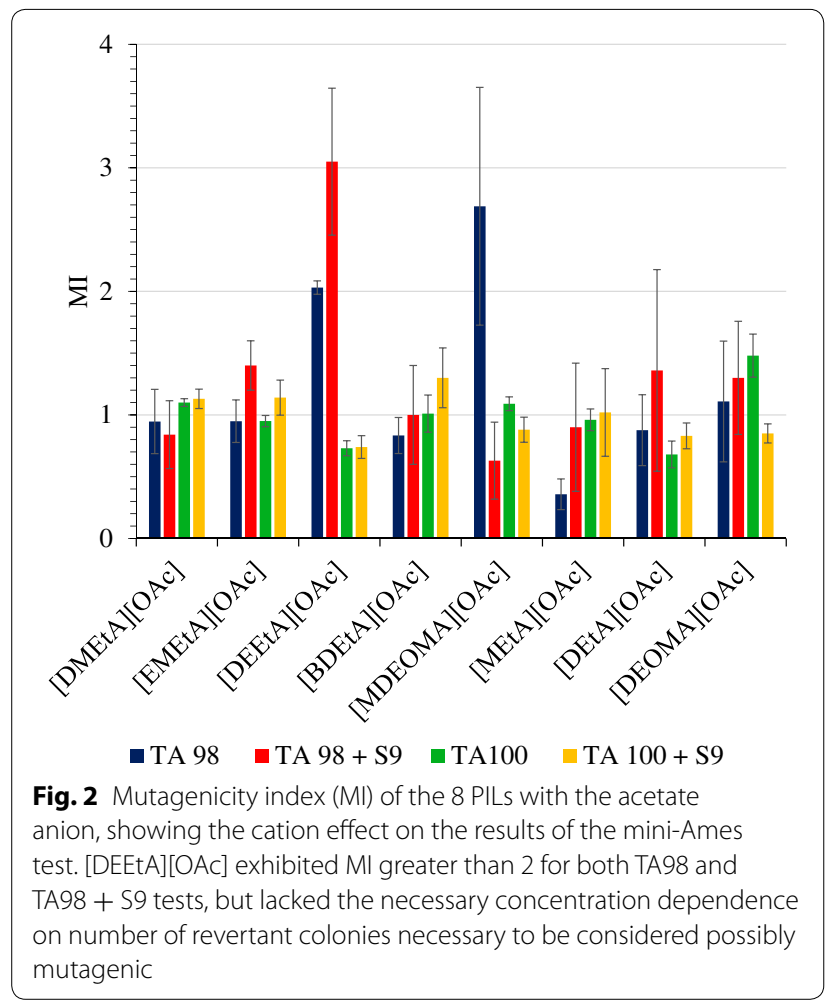

By substituting the hydroxyl component of the cation with a methoxy ether group, we increase the lipophilicity (by limiting the hydrogen bonding capability of the cation) while still incorporating oxygen into the PIL structure. This is a useful technique that is commonly utilised when designing readily biodegradable ILs, an important consideration to make in the design of new solvent technology $[64,65]$. However, it has been suggested that methoxy functional groups can be mutagenic, as has been observed with methyl tertiary butyl ether in the unscheduled DNA synthesis assay test [66]. From our results, we observe a higher MI from the TA98 test for [MDEOMA] [OAc] than compared to any other PIL (aside from [DEEtA][OAc]) but again lacked the necessary MAR to be deemed possibly mutagenic to this test strain. Aside from this result, [MDEOMA][OAc] has comparable MI (Fig. 2) and MAR (Fig. 3) values for all other tests to all hydroxyl functionalised cation PILs.

One of the questions we wish to address in this study is the difference in mutagenicity between secondary and tertiary ammonium PILs. Some secondary amines have been found to readily convert to $\mathrm{N}$-nitrosamine compounds both in vivo and in vitro, which are virulently carcinogenic [67-69]. Additionally, diethanolamine has been determined to be possibly carcinogenic to humans (group 2B) by the International Agency for Research on Cancer [70]. This is despite the pass result

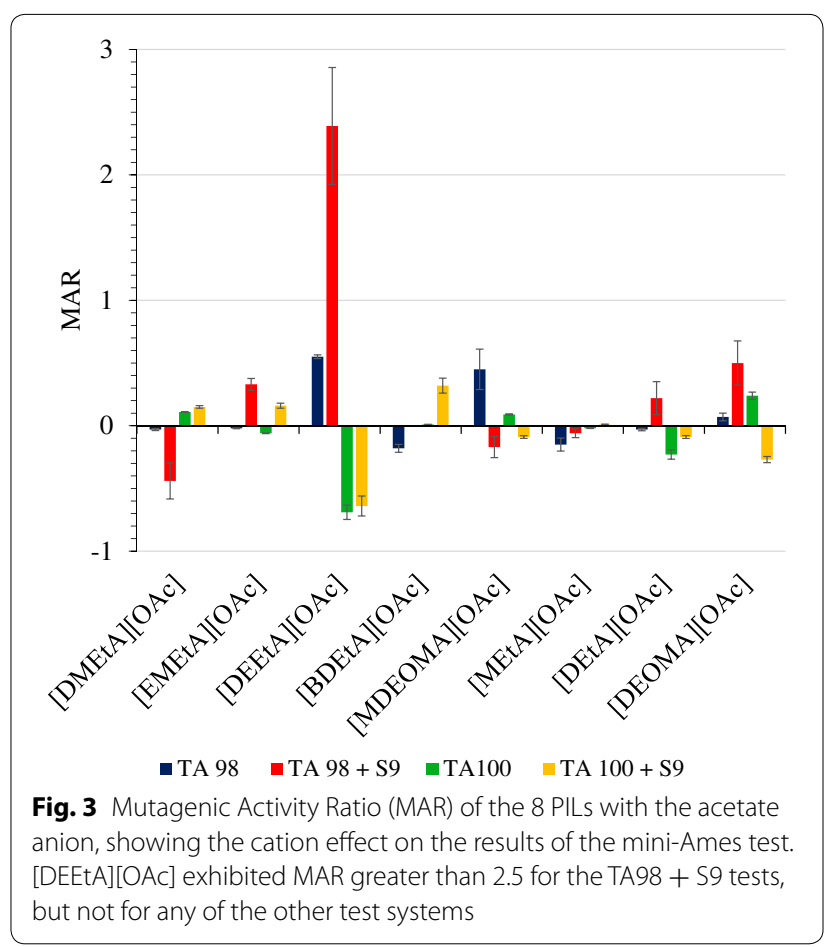

given to previous Ames test investigations of diethanolamine [57]. Because of this concern, in addition to the PILs we also included the precursor amines diethanolamine and $\mathrm{N}, \mathrm{N}$-dimethylethanolamine into our mini Ames test screening. Both the precursor diethanolamine and the PIL [DEtA][OAc] showed that they are not likely to be either mutagenic according to the mini Ames test (Figs. 2, 3). We have already cautioned the use of results from the mini Ames test as a direct comparison to the mutagenicity potential of a compound. We conclude that more information is required before we can confirm the mutagenicity potential of diethanolammonium PILs. We remind here that the concentration of PILs in the test systems are typically less than $0.05 \mathrm{~mol} \mathrm{dm}^{-3}$. At these low concentrations, the structure of the individual ions will be more likely to govern mutagenicity rather than their tendency to form aqueous aggregates.

\section{Variation of the anion: carboxylate anions}

Seven of the tested PILs were based on the N,N-dimethylethanolammonium cation, in combination with various anions (Figs. 4, 5). This facilitated a basic assessment of the effects of anion alkyl chain length and functionality on mutagenicity, as well as on any direct toxicity to the test organisms. The shorter-chain anions showed little correlation between chain length and either MI or MAR in either test strains. Indeed, it would have been extraordinary had any increase in mutagenicity directly 

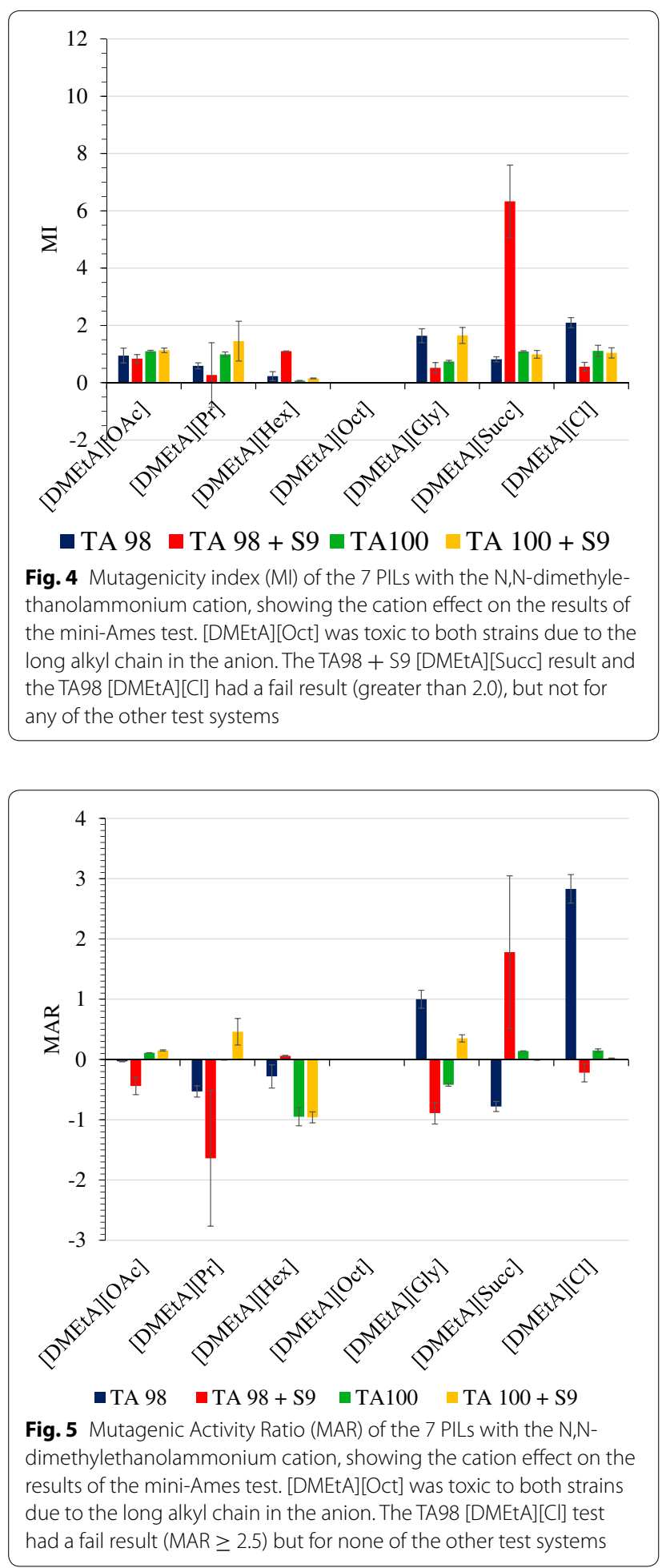

attributable to such ubiquitous (and metabolicallyessential) anions as acetate and succinate been indicated. $N, N$-Dimethylethanolammonium octanoate ([DMEtA] [Oct]) was toxic to both strains at all concentrations, hence could not be screened for mutagenicity. The long aliphatic chain on the anion of this particular PIL is characteristic of anionic surfactants, which are obviously well established antimicrobial agents, hence this result was anticipated; similar effects having also been observed with other long chain alkyl-substituted ILs [71].

\section{Variation of anion: chloride vs. acetate}

Unsurprisingly, only one of the test results showed any difference between acetate and chloride, this being a positive result $[\mathrm{MI} \geq 2.0$ (Fig. 6) and MAR $\geq 2.5$ (Fig. 7)] seen with $[\mathrm{DMEtA}][\mathrm{Cl}]$ with the TA98 strain alone, and not with [DMEtA][OAc]. However, this result lacked the linear relationship between concentration and number of revertant colonies necessary for it to be considered mutagenic. Again, we observe little difference in test results for all strains between secondary and tertiary ammonium cations, as well as between hydroxyl functionalised and methoxy functionalised cations.

\section{Conclusions}

Of the 16 PILs tested, 15 were shown to be non-mutagenic in the mini-Ames test and may thus be considered unlikely to exhibit mutagenic or carcinogenic activity, within the accepted limitations of the test methodology. [DMEtA][Oct] was toxic to both S. typhimurium strains

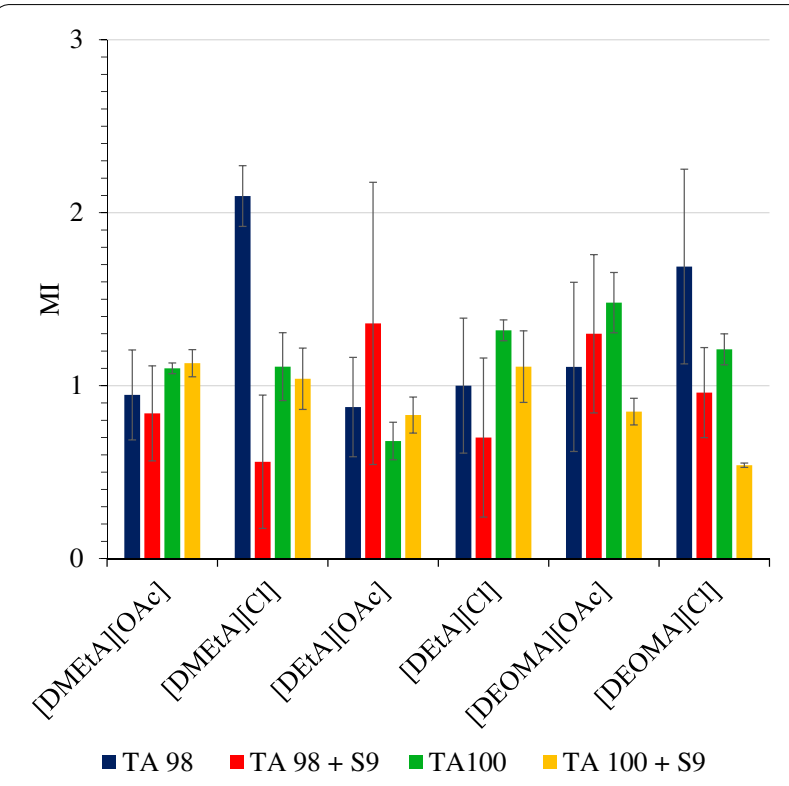

Fig. 6 Mutagenicity index (MI) of 6 PILs, featuring either an acetate or chloride anion, hydroxyl or ether functionalised groups on the cation and either secondary or tertiary ammonium cations. By changing between the acetate and chloride anion, there is little change in the MI. Secondary ammonium cation PILs show a comparable MI result to tertiary ammonium cation PILs in the mini Ames test. Methoxy ether functional groups also appear to have little impact on the Ml of the PIL 


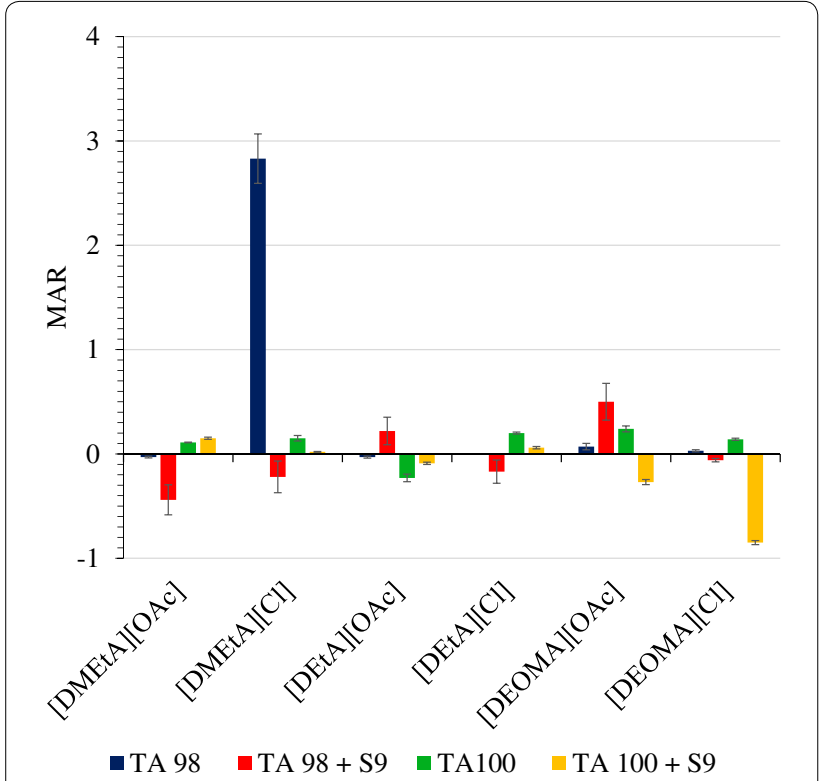

Fig. 7 Mutagenic Activity Ratio (MAR) of 6 PILs, featuring either an acetate or chloride anion, hydroxyl or ether functionalised groups on the cation and either secondary or tertiary ammonium cations. Aside from the TA $98[D M E t A][C l]$ result, all tests

in the mini Ames test due to the long alkyl chain on the carboxylate anion, and could therefore not be tested for mutagenicity by this test. All other PILs failed to meet all three of the requirements to be deemed potentially mutagenic or carcinogenic in accordance with the mini Ames test. However, because of the likely state of these PILs in physiological conditions being very similar to that of their precursors, we caution the use of secondary ammonium cation PILs as certain secondary amines. For example, it has been shown previously that diethanolamine have been deemed potentially carcinogenic to humans (group 2B). This is contradictory to our results for diethanolamine in the mini Ames test, which agree with prior Ames test results for diethanolamine. We propose that more in-depth mutagenicity studies into PILs should be carried out to either challenge or confirm the results of the mini Ames test. Ultimately, we conclude that the potential mutagenicity of carboxylate ammonium PILs can be treated as the same as that of their precursors due to the likely highly diluted state of both ions.

\section{Additional file}

Additional file 1. The complete data of all compounds screened with the mini Ames test in this study.

\section{Authors' contributions}

JESJR drafted the manuscript with input from AJW and SS, LS and GAH prepared all PILs in this study, NS was responsible for screening of all compounds with the mini Ames test and SS and AJW supervised the entire study. All authors read and approved the final manuscript.

\section{Author details}

${ }^{1}$ York Structural Biology Laboratory, Department of Chemistry, University of York, Heslington, York YO10 5DD, UK. ${ }^{2}$ TWI Ltd., Granta Park, Great Abington, Cambridge CB21 6AL, UK. ${ }^{3}$ The Durham Genome Centre, Park House, Station Road, Lanchester DH7 OEX, UK. ${ }^{4}$ St. Saviour's and St. Olave's School, London SE1 4AN, UK. ${ }^{5}$ University of Hull, Kingston-upon-Hull HU6 7RX, UK.

\section{Acknowledgements}

The authors gratefully acknowledge the financial support of the Engineering and Physical Sciences Research Council (EPSRC) through an industrial CASE award. All data supporting this study are provided as tables in the main paper and as supplementary information accompanying this paper. We gratefully acknowledge Complement Genomics Ltd. in undertaking mini Ames screening of all compounds within this study.

\section{Competing interests}

The authors declare that they have no competing interests.

Received: 15 July 2015 Accepted: 7 November 2015

Published online: 25 November 2015

\section{References}

1. Clark JH (1999) Green chemistry: challenges and opportunities. Green Chem 1:1-8

2. Postle M, Holmes P, Salado R, Thorell A, Tuffnell N, Guittat A, Fantke P, Rushton L (2011) Assessing the health and environmental impacts in the context of socio-economic analysis under REACH; Part 1: literature review and recommendations, European Chemicals Agency. Accessed 25th June 2015

3. Eckert CA, Knuston BL, Debendetti PG (1996) Supercritical fluids as solvents for chemical and materials processing. Nature 383:313-318

4. Hallett JP, Welton T (2011) Room-temperature ionic liquids: solvents for synthesis and catalysis. 2. Chem Rev 111:3508-3576

5. Clark JH, Tavener SJ (2007) Alternative solvents: shades of green. Org Process Res Dev 11:149-155

6. Burrell GL, Burgar IM, Separovic F, Dunlop NF (2010) Preparation of protic ionic liqids with minimal water content and ${ }^{15} \mathrm{~N}$ NMR study of proton transfer. Phys Chem Chem Phys 12:1571-1577

7. Seddon KR, Stark A, Torres MJ (2000) Influence of chloride, water, and organic solvents on the physical properties of ionic liquids. Pure Appl Chem 72:2275-2287

8. Reid JESJ, Walker AJ, Shimizu S (2015) Residual water in ionic liquids: clustered or dissociated? Phys Chem Chem Phys 17:14710-14718

9. Chen L, Sharifzadeh M, Mac Dowell N, Welton T, Shah N, Hallett JP (2014) Inexpensize ionic liquids: $\left[\mathrm{HSO}_{4}\right]^{-}$based solvent production at bulk scale. Green Chem. 16:3098-3106

10. George A, Brandt A, Tran K, Zahari SMSNS, Klein-Marcuchamer D, Sun N, Sathitsuksanoh N, Shi J, Stavila V, Parthasarathi R, Singh S, Holmes BM, Welton T, Simmons BA, Hallett JP (2015) Design of low-cost ionic liquids for lignocellulosic biomass pretreatment. Green Chem. 17:1728-1734

11. Walden P (1914) Molecular weights and electrical conductivity of several fused salts. Bull Acad Imper Sci (St. Petersburg) 8:405-422

12. Walker AJ (2007) Protic ionic liquids and their potential industrial applications. Chim Oggi 5:17-19

13. Walker AJ, inventor; Innovia Films Limited, assignee (2004) Ionic liquids comprising nitrogen containing cations. European patent EP 1805131 B1

14. Angell CA, Byrne N, Belieres JP (2007) Parallel developments in aprotic and protic ionic liquids: physical chemistry and applications. Acc Chem Res 40:1228-1236

15. Greaves TL, Drummond CJ (2008) Protic ionic liquids: properties and applications. Chem Rev 108:206-237

16. Angell CA, Ansari Y, Zhao Z (2012) lonic liquids: past, present and future. Faraday Discuss 154:9-27 
17. MacFarlane DR, Tachikawa N, Forsyth M, Pringle JM, Howlett PC, Elliott GD, Davis JH Jr, Watanabe M, Simon P, Angell CA (2014) Energy applications of ionic liquids. Energy Environ Sci 7:232-250

18. Hunt PA, Ashworth CR, Matthews RP (2015) Hydrogen bonding in ionic liquids. Chem Soc Rev 44:1257-1288

19. Sanders MW, Wright L, Tate L, Fairless G, Crowhurst L, Bruce NC, Walker AJ, Hembury GA, Shimizu S (2009) Unexpected preferential dehydration of artemisinin in ionic liquids. J Phys Chem A 133:10143-10145

20. Chi YS, Zhang ZD, Li CP, Liu QS, Yan PF, Welz-Biermann U (2011) Microwave-assisted extraction of lactones from Ligusticum chuanxiong Hort. using protic ionic liquids. Green Chem 13:666-670

21. Goujon N, Wang X, Rajkowa R, Byrne N (2012) Regenerated silk fibroin using protic ionic liquids solvents: towards an all-ionic-liquid process for producing silk with tunable properties. Chem Commun 48:1278-1280

22. Idris A, Vijayaraghavan R, Patti AF, MacFarlane DR (2014) Distillable protic ionic liquids for keratin dissolution and recovery. ACS Sustain Chem Eng. 2:1888-1894

23. Achinivu EC, Howard RM, Li G, Gracz H, Henderson WA (2014) Lignin extraction from biomass with protic ionic liquids. Green Chem 16:1114-1119

24. Verdía P, Brandt A, Hallett JP, Ray MJ, Welton T (2014) Fractionation of lignocellulosic biomass with the ionic liquid 1-butylimidazolium hydrogen sulfate. Green Chem 16:1617-1627

25. Li Z, Li C, Chi Y, Wang A, Zhang Z, Li H, Liu Q, Welz-Biermann U (2012) Extraction process of dibenzothiophene with new distillable aminebased protic ionic liquids. Energy Fuels 26:3723-3727

26. Lü H, Wang S, Deng C, Ren W, Guo B (2014) Oxidative desulfurization of model diesel via dual activation by a protic ionic liquid. J Hazard Mater 279:220-225

27. Li Z, Xu J, Li C (2015) Extraction process of sulfur compounds from fuels with protic ionic liquids. RSC Adv. 5:15892-15897

28. Yokozeki A, Shiflett MB (2007) Vapor-liquid equilibria of ammonia + ionic liquid mixtures. Appl Energy 84:1258-1273

29. Mumford KA, Pas SJ, Linseisen T, Statham TM, Nicholas NJ, Lee A, Kezia K, Vijayraghavan R, MacFarlane DR, Stevens GW (2015) Evaluation of the protic ionic liquid, N, N-dimethyl-aminoethylammonium formate for CO2 capture. Int J Greenhouse Gas Control 32:129-134

30. Vijayraghavan R, Pas SJ, Izgorodina El, MacFarlane DR (2013) Diamino protic ionic liquids for $\mathrm{CO}_{2}$ capture. Phys Chem Chem Phys 15:19994-19999

31. Nakamoto H, Watanabe M (2007) Bronsted acid-base ionic liquids for fuel cell electrolytes. Chem Comm. 24:2539-2541

32. Lee SY, Ogawa A, Kanno M, Nakamoto H, Yasuda T, Watanbe M (2010) Nonhumidified intermediate temperature fuel cells using protic ionic liquids. J Am Chem Soc 132:9764-9773

33. Snyder J, Fujita T, Chen MW, Erlebacher J (2010) Oxygen reduction in nanoporous metal-ionic liquid composite electrocatalysts. Nat Mater 9:904-907

34. Olivier-Bourbigou H, Manga L, Morvan D (2010) lonic liquids and catalysis: recent progress from knowledge to applications. Appl Catal A-Gen. 373:1-56

35. Clark JH, Farmer TJ, Macquarrie DJ, Sherwood J (2013) Using metrics and sustainability considerations to evaluate the use of bio-based and nonrenewable Brønsted acidic ionic liquids to catalyse Fischer esterification reactions. Sustain Chem Process. 1:23-35

36. Qu J, Truhan JJ, Dai S, Luo H, Blau PJ (2006) lonic liquids with ammonium cations as lubricants or additives. Tribol Lett 22:207-214

37. Kondo H (2008) Protic ionic liquids with ammonium salts as lubricants for magnetic thin film media. Tribol Lett 31:211-218

38. Zhao Q, Zhao G, Zhang M, Wang X, Liu W (2012) Tribological behavior of protic ionic liquids with dodecylamine salts of dialkyldithiocarbamate as additives in lithium complex grease. Tribol Lett 48:133-144

39. Espinosa $T$, Jimenez M, Sanes J, Jimenez AE, Inglesias M, Bermudez MD (2014) Ultra-low friction with a protic ionic liquid boundary film at the water-lubricated sapphire-stainless steel interface. Tribol Lett 53:1-9

40. Kondo H, Ito M, Hatsuda K, Yun K, Watanabe M (2013) Novel ionic lubricants for magnetic thin film media. IEEE Trans Magnet. 49:3756-3759

41. Luo H, Yu M, Dai S (2007) Solvent extraction of $\mathrm{Sr}^{2+}$ and $\mathrm{Cs}^{+}$based on hydrophobic protic ionic liquids. Z Naturforsch A. 62:281-291

42. Katsuta S, Yoshimoto Y, Okai M, Takeda Y, Bessho K (2011) Selective extraction of palladium and platinum from hydrochloric acid solutions by trioctylammonium-based mixed ionic liquids. Ind Eng Chem Res 50:12735-12740

43. Katsuta S, Okai M, Yoshimoto Y, Kudo Y (2012) Extraction of gallium(III) from hydrochloric acid solutions by trioctylammonium-based mixed ionic liquids. Anal Sci 28:1009-1012

44. Watanabe Y, Araki Y, Katsuta S (2014) Extraction behaviour of gold (III) from hydrochloric acid solutions by protic ionic liquids. Bunseki Kagaku 63:563-567

45. Peric B, Martí E, Sierra J, Cruañas R, Inglesias M, Garau MA (2011) Terrestrial ecotoxicity of short aliphatic protic ionic liquids. Ecotoxicol Environ Saf 30:2802-2809

46. Peric B, Sierra J, Martí E, Cruañas R, Garau MA, Arning J, Bottin-Weber U, Stolte $S$ (2013) (Eco)toxicity and biodegradability of selected protic and aprotic ionic liquids. J Hazard Mater 261:99-105

47. Peric B, Sierra J, Martí E, Cruañas R, Garau MA (2014) A comparative study of the terrestrial ecotoxicity of selected protic and aprotic ionic liquids. Chemosphere 108:418-425

48. Peric B, Martí E, Sierra J, Cruañas R, Inglesias M, Garau MA (2015) Quantitative structure-activity relationship (QSAR) prediction of (eco)toxicity of short aliphatic protic ionic liquids. Ecotoxicol Environ Saf 115:257-262

49. Ames BN, McCann J, Yamasaki E (1975) Methods for detecting carcinogens and mutagens with salmonella-mammalian-microsome mutagenicity test. Mutat Res 31:347-363

50. McCann J, Choi E, Yamasaki E, Ames BN (1975) Detection of carcinogens as mutagens in salmonella microsome test-assay of 300 chemicals. Proc Nat Acad Sci USA 72:5135-5139

51. Maron DM, Ames BN (1983) Revised methods for the salmonella mutagenicity test. Mutat Res 113:173-215

52. Mortelmans K, Zeiger E (2000) The Ames Salmonella/microsome mutagenicity assay. Mutat Res-Fund Mol M. 455:29-60

53. Maron DM, Katzenellenbogen J, Ames BN (1981) Compatability of organic-solvents with the salmonella-microsome test. Mutat Res 88:343-350

54. Docherty KM, Hebbeler SZ, Kupla CF Jr (2006) An assessment of ionic liquid mutagenicity using the Ames test. Green Chem 8:560-567

55. McCann J, Spingarn N, Kobori J, Ames BN (1975) Detection of carcinogens as mutagens: bacterial tester strains with R Factor plasmids. Proc Natl Acad Sci USA 72:979-983

56. Kirkland DJ (1989) Guidelines for mutagenicity testing part II. Statistical evaluation of mutagenicity test data, 1st edn. Cambridge University Press, Cambridge

57. Haworth S, Lawlor T, Mortelmans K, Speck W, Zeiger E (1983) Salmonella mutagenicity test results for 250 chemicals. Environ Mol Mutagen 5:3-142

58. Zeiger E, Anderson B, Haworth S, Lawlor T, Mortelmans K, Speck W (1987) Salmonella mutagenicity tests. 3. Results from the testing of 255 chemicals. Environ Mol Mutagen 9:1-109

59. Zeiger E, Anderson B, Haworth S, Lawlor T, Mortelmans K (1992) Salmonella mutagenicity tests. 5. Results from the testing of 311 chemicals. Environ Mol Mutagen 19:2-141

60. Fujita H, Sumi C, Sasaki M (1992) Mutagenicity test of food additives with Salmonella typhimurium TA97 and TA102. Ann Rep Tokyo Metrop Res Lab Public Health. 43:219-227

61. Stange P, Fumino K, Ludwig R (2013) Ion speciation of protic ionic liquids in water: transition from contact to solvent-separated ion pairs. Angew Chem Int Ed 52:2990-2994

62. Stolte S, Matzke M, Arning J, Böschen A, Pitner W, Welz-Biermann U, Jastorff B, Ranke J (2007) Effects of different head groups and functionalised side chains on the aquatic toxicity of ionic liquids. Green Chem 9:1170-1179

63. Pham TPT, Cho C, Yun Y (2010) Environmental fate and toxicity of ionic liquids: a review. Water Res 44:352-372

64. Coleman D, Gathergood N (2010) Biodegradation studies of ionic liquids. Chem Soc Rev 39:600-637

65. Jordan A, Gathergood N (2015) Biodegradation of ionic liquids-a critical review. Chem. Soc, Rev

66. Zhou W, Yuan D, Huang G, Zhang H, Ye S (2000) Mutagenicity of methyl tertiary butyl ether. J Environ Pathol Toxicol Oncol 19:35-39

67. Greenbla M, Mirvish S, So BT (1971) Nitrosamine studies_induction of lung adenomas by concurrent administration of sodium nitrate and secondary amines in swiss mice. J Natl Cancer Inst 46:1029-1034 
68. Hawkswor GM, Hill MJ (1971) Bacteria and N-nitrosation of secondary amines. Brit J Cancer. 25:520-526

69. Szylit O, Ducluzeau R, Champ M, Klein D (1976) La formation des nitrosamines dans le tube digestif. Ann Nutr Aliment. 30:805-812

70. Some chemicals present in industrial and consumer products, food and drinking-water, IARC monographs on the evaluation of carcinogenic risks to humans; International Agency for Research on Cancer; World Health
Organisation. 2012. http://monographs.iarc.fr/ENG/Monographs/vol101/ mono101.pdf. Accessed 26 June 2015

71. Garcia MT, Gathergood N, Scammells PJ (2005) Biodegradable ionic liquids - Part II. Effect of the anion and toxicology. Green Chem 7:9-14

\section{Publish with ChemistryCentral and every} scientist can read your work free of charge

"Open access provides opportunities to our colleagues in other parts of the globe, by allowing anyone to view the content free of charge."

W. Jeffery Hurst, The Hershey Company.

- available free of charge to the entire scientific community

- peer reviewed and published immediately upon acceptance

- cited in PubMed and archived on PubMed Central

- yours - you keep the copyright

Submit your manuscript here:

http://www.chemistrycentral.com/manuscript/

ChemistryCentral 